\title{
Serum paraprotein persistence and size determine outcome in a cohort of patients with a modern definition of plasmacytoma with up to 19 years of follow up
}

\author{
Elisabet E. Manasanch $\mathbb{D}^{1}$, Chutima Kunacheewa $\mathbb{0}^{1,2}$, Catherine M. Claussen', Hans C. Lee', Sheeba K. Thomas',

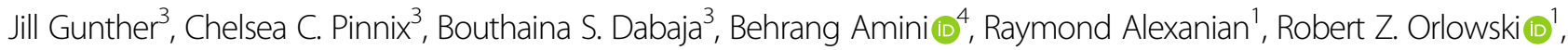 \\ Wenli Dong ${ }^{5}$, Lei Feng ${ }^{5}$ and Donna M. Weber ${ }^{1}$
}

Dear Editor,

Solitary plasmacytoma (SP) is a rare plasma cell disorder ( $<5 \%$ of all plasma cell dyscrasias) that consists of solitary bone plasmacytoma (SBP) and solitary extramedullary plasmacytoma (SEP). Local control with radiation therapy (RT) remains the standard of care. About half of all patients progress to multiple myeloma (MM) within 3-5 years after diagnosis ${ }^{1}$. Several factors identify SP patients that are at high risk of progression to MM (location, bone marrow (BM) involvement, serum free light chain values (sFLC), paraprotein persistence, and size). Identification of patients at high risk of progression to $\mathrm{MM}$ is an important step to design prevention strategies. In smoldering myeloma, randomized studies have shown increased progression-free survival (PFS) and overall survival (OS) after systemic treatment ${ }^{2,3}$ and immunotherapeutic strategies in this space are promising ${ }^{4,5}$. Due to a limited number of cases, prospective evaluation of prevention strategies in SP has remained elusive.

We retrospectively reviewed medical records of patients treated between 1986 and 2015 in our institution's database. Patients met diagnostic criteria of SP according to the International Myeloma Working Group 2014 ${ }^{6} .218$ patients were identified, and 147 excluded (Fig. S1). At

\footnotetext{
Correspondence: Elisabet E. Manasanch (eemanasanch@mdanderson.org) 'Department of Lymphoma/Myeloma, The University of Texas MD Anderson Cancer Center, Houston, TX, USA

${ }^{2}$ Faculty of Medicine Siriraj Hospital, Division of Hematology, Mahidol University, Salaya, Thailand

Full list of author information is available at the end of the article These authors contributed equally: Elisabet E. Manasanch, Chutima Kunacheewa
}

baseline, patients were evaluated to exclude systemic involvement by ${ }^{1}$ bone marrow biopsy to evaluate plasma cell involvement by IHC and at least 4-color flow cytometry (FC) including CD138, CD38, CD19, CD56, and CD $33^{2}$; skeletal survey and advanced imaging -computed tomography $(\mathrm{CT})$, magnetic resonance imaging (MRI), and/or positron emission tomography/CT (PETCT). Development of either a new SP outside the area of radiation, multiple plasmacytomas, or SLiM CRAB criteria attributed to underlying plasma cell dyscrasia was considered progression to MM.

The primary objective of the study is to describe a model with variables that affect progression from SP to MM. Additionally, we aimed to assess the time to myeloma progression (TTM: time from diagnosis to myeloma progression), PFS (time from diagnosis to myeloma progression or death), and OS (time from diagnosis to death from any cause). $X^{2}$ test and Fisher's exact test were used to evaluate the association between categorical variables. Wilcoxon's rank sum test was used to compare continuous variables between two different groups. TTM, PFS, and OS were evaluated by Kaplan-Meier curves and log-rank test. In the process of fitting the multi-covariate Cox regression model, a backwards variable selection was used with a $p$-value $\leq 0.05$ as the limit for inclusion in the model for predicting risk of progression to MM and a $p$ value threshold of 0.2 for PFS and OS.

Seventy-one patients (50 SBP and $21 \mathrm{SEP}$ ) met inclusion criteria (Table 1). At median follow-up of 9.4 years (0.3-19.5 years), 35 patients progressed to MM, 28/50 $(56 \%)$ patient in SBP and 7/21 (33\%) patients in SEP $(p=$ 
Table 1 Baseline patients' characteristics and treatment profiles.

\begin{tabular}{|c|c|c|c|c|}
\hline & $\begin{array}{l}\text { All, } n \text { (\%) } \\
n=71\end{array}$ & $\begin{array}{l}\text { SBP, } n(\%) \\
n=50\end{array}$ & $\begin{array}{l}\text { SEP, } n(\%) \\
n=21\end{array}$ & $P$-value \\
\hline $\begin{array}{l}\text { Age, median } \\
(\min , \max )\end{array}$ & $58(32-83)$ & $57(36-83)$ & $61(32-75)$ & 0.588 \\
\hline Sex, male & $51(70)$ & $31(62)$ & $20(95)$ & 0.005 \\
\hline Imaging $^{a}$ & & & & NA \\
\hline $\mathrm{PET} / \mathrm{CT}$ & $26(37)$ & $20(40)$ & $6(29)$ & \\
\hline MRI & $63(88)$ & $47(94)$ & $16(76)$ & \\
\hline $\mathrm{CT}$ & $44(62)$ & $29(58)$ & $15(71)$ & \\
\hline Bone survey & $38(53)$ & $39(78)$ & $16(76)$ & \\
\hline Advance imaging ${ }^{b}$ & $71(100)$ & $50(100)$ & $21(100)$ & \\
\hline M-protein, positive & $30(46)$ & $26(58)$ & $4(19)$ & 0.003 \\
\hline $\begin{array}{l}\text { M-protein, level; } \\
\text { median (min, max) }\end{array}$ & $0(0-2)$ & $0.3(0-2)$ & $0(0-0.6)$ & 0.006 \\
\hline M-protein $>0.7 \mathrm{~g} / \mathrm{dL}$ & $13(19)$ & $12(25)$ & $1(5)$ & 0.05 \\
\hline Serum IFE, positive & $67(94)$ & $47(94)$ & $20(95)$ & 0.838 \\
\hline $\begin{array}{l}\text { sFLC ratio (involved/ } \\
\text { uninvolved) ( } n=43 \text { ) }\end{array}$ & $\begin{array}{l}2.3 \\
(1.1-148)\end{array}$ & $\begin{array}{l}2.3 \\
(1.1-148)\end{array}$ & $\begin{array}{l}1.3 \\
(1.1-3.4)\end{array}$ & 0.119 \\
\hline $\begin{array}{l}\text { Urine IFE, positive } \\
(n=64)\end{array}$ & $26(40)$ & $20(44)$ & $6(32)$ & 0.342 \\
\hline $\begin{array}{l}\text { Bence Jones Protein, } \\
\text { positive }(n=66)\end{array}$ & $21(32)$ & $17(37)$ & $4(20)$ & 0.295 \\
\hline $\begin{array}{l}\text { Occult marrow } \\
\text { disease }^{c} \\
\text { positive by MFC }\end{array}$ & $7(10)$ & $6(12)$ & $1(5)$ & 0.345 \\
\hline Location & & & & $<0.001$ \\
\hline Head and neck & $21(30)$ & $2(4)$ & $19(91)$ & \\
\hline Spine & $15(21)$ & $15(30)$ & 0 & - \\
\hline Pelvis & $10(14)$ & $10(20)$ & 0 & - \\
\hline Lower extremities & $7(10)$ & $7(14)$ & 0 & - \\
\hline Upper extremities & $7(10)$ & $7(14)$ & 0 & - \\
\hline Chest & $8(11)$ & $7(14)$ & $1(5)$ & - \\
\hline Abdomen & $3(4)$ & $2(4)$ & $1(5)$ & - \\
\hline $\begin{array}{l}\text { Size, median (range) } \\
\quad>5 \mathrm{~cm}\end{array}$ & $4(1-17)$ & $5(1-17)$ & $3(1-10)$ & 0.087 \\
\hline $\begin{array}{l}\text { Immunoparesis }^{d} \\
(n=67)\end{array}$ & $6(9)$ & $4(9)$ & $2(10)$ & 0.913 \\
\hline 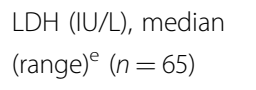 & $\begin{array}{l}465 \\
(331-818)\end{array}$ & $\begin{array}{l}447 \\
(331-818)\end{array}$ & $\begin{array}{l}481 \\
(370-566)\end{array}$ & 0.914 \\
\hline $\begin{array}{l}\text { B2 microglobulin } \\
\text { (mg/L), median } \\
\text { (range) }\end{array}$ & $2(1.2-4.1)$ & $2(1.2-3.6)$ & $2(1.4-4.1)$ & 0.883 \\
\hline
\end{tabular}

Table 1 continued

\begin{tabular}{|c|c|c|c|c|}
\hline & $\begin{array}{l}\text { All, } n(\%) \\
n=71\end{array}$ & $\begin{array}{l}\text { SBP, } n(\%) \\
n=50\end{array}$ & $\begin{array}{l}\text { SEP, } n(\%) \\
n=21\end{array}$ & $P$-value \\
\hline $\begin{array}{l}\text { Albumin (g/dL), } \\
\text { median (range) }\end{array}$ & $\begin{array}{l}4.4 \\
(2.2-5.4)\end{array}$ & $4(2.2-5.2)$ & $4(3.1-5.4)$ & 0.709 \\
\hline $\begin{array}{l}\text { Persistence of serum } \\
\text { paraprotein } 1 \text { year } \\
\text { after treatment }(n= \\
61 \text { ) }\end{array}$ & $19(31)$ & $18(41)$ & $1(6)$ & 0.052 \\
\hline \multicolumn{5}{|l|}{ Treatment $(n=71)$} \\
\hline Radiation alone & $52(74)$ & $42(84)$ & $10(47)$ & - \\
\hline RT + surgery & $13(19)$ & $6(12)$ & $7(33)$ & NA \\
\hline $\begin{array}{l}\text { RT }+ \\
\text { chemotherapy }^{f}\end{array}$ & $1(1)$ & 0 & $1(5)$ & - \\
\hline $\begin{array}{l}\text { RT }+ \text { surgery }+ \\
\text { chemotherapy }^{f}\end{array}$ & $1(1)$ & 0 & $1(5)$ & - \\
\hline Surgery alone & $4(6)$ & $2(4)$ & $2(9)$ & - \\
\hline $\begin{array}{l}\text { Radiation dose, } \\
\text { median (range) Gy }\end{array}$ & $45(24-50)$ & $45(24-50)$ & $45(40-50)$ & 0.161 \\
\hline
\end{tabular}

Abbreviations: $B M$, bone marrow; $C T$, computed tomography; $L D H$, lactase dehydrogenase; MRI, magnetic resonance imaging; NA, not applicable; $P E T / C T$, positron emission tomography-computed tomography; $R T$, radiation therapy; $M F C$, multicolor flow cytometry; $I H C$, immunohistochemistry; $P C$, plasma cell ${ }^{a}$ Available at our institution since: 1986 (bone survey x-rays and CT scan), 1988 (MRI), 2005 (PETCT).

${ }^{\mathrm{b}}$ Advance imaging including $\mathrm{CT}, \mathrm{MRI}$, or $\mathrm{PET} / \mathrm{CT}$

'Occult marrow disease was tested by MFC in 71 patients who all had $\leq 5 \%$ plasma cells in the bone marrow core biopsy by immunohistochemistry ${ }^{d}$ Immunoparesis was defined as level of $\geq 1$ uninvolved immunoglobulin below the lower level of normal

${ }^{\mathrm{e}} \mathrm{LDH}$ institutional normal range is $135-225 \mathrm{IU} / \mathrm{L}$

${ }^{f}$ Chemotherapy consisted of CHOP, Taxol, melphalan, and modified cyclophosphamide, bortezomib, Adriamycin, dexamethasone (CVAD)

Due to large number of years of follow up and retrospective nature of the study, not all patients had information for all variables. Variables with and additional $(n=)$ list the number of patients for whom the variable information is available. If no additional $(n=)$ is present, then that particular variable's information is available for all 71 patients

0.083; Fig. S2). In all, 3-, 5-, and 10-year TTM rate were $34 \%, 38 \%$, and $50 \%$ for the entire cohort (Table S1). The median TTM for the entire patient cohort was not reached (NR) and was shorter in SBP patients (6.7 years) than SEP patients (NR; $p=0.138$ ). All SEP patients who progressed to myeloma did so within 5 years of diagnosis. Similar results were reported that showed that $84 \%$ of patients with SEP progressed within the first 3 years of the diagnosis $^{7}$. In contrast, in our series, SBP patients continued to progress after 14 years of diagnosis.

The presence of SMP at baseline and 1 year after treatment and plasmacytoma size of $\geq 10 \mathrm{~cm}$ were associated with increased risk of progression to MM. Patients who had presence of a serum monoclonal protein (SMP) at baseline and a plasmacytoma size of $\geq 10 \mathrm{~cm}$, compared to those who did not, had a lower median TTM of 5.3 years versus NR $(p=0.002)$, and 1.5 years versus NR $(p=$ 


\begin{tabular}{|l|c|c|c|c|c|c|}
\hline $\begin{array}{l}\text { Number of } \\
\text { risk factors }\end{array}$ & $\begin{array}{c}\text { Total } \\
\text { number } \\
\text { of } \\
\text { patients }\end{array}$ & $\begin{array}{c}\text { Number of } \\
\text { patients with } \\
\text { progression } \\
\text { to MM }\end{array}$ & $\begin{array}{c}\text { Median time to } \\
\text { progression to } \\
\text { MM (months) }\end{array}$ & $\begin{array}{c}\text { Rate of } \\
\text { progression at 3 } \\
\text { years from } \\
\text { diagnosis }\end{array}$ & $\begin{array}{c}\text { Rate of } \\
\text { progression at 5 } \\
\text { years from } \\
\text { diagnosis }\end{array}$ & $\begin{array}{c}\text { Rate of } \\
\text { progression at 10 } \\
\text { years from } \\
\text { diagnosis }\end{array}$ \\
\hline 0 & 43 & 14 & NR & 19 & 30 & 39 \\
\hline 1 or 2 & 23 & 19 & 1.8 & 65 & 70 & 82 \\
\hline All Patients & 66 & 43 & 10 & 34 & 38 & 50 \\
\hline
\end{tabular}

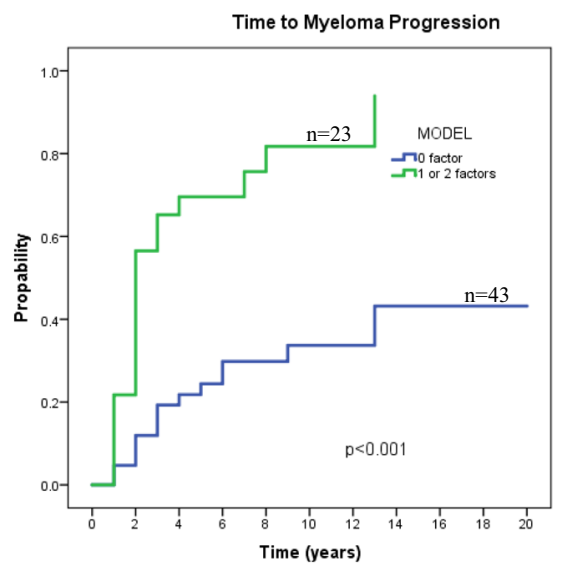

Fig. 1 Model of high and low-risk SP by two risk factors (plasmacytoma size $>\mathbf{1 0} \mathbf{~ c m}$. At diagnosis and persistent serum paraprotein 1 year after treatment) divided in to 2 groups: 0 risk factors and 1 and/or 2 risk factors. The rate of progression to MM was significantly higher in patients who had either a plasmacytoma size of $\geq 10 \mathrm{~cm}$ at diagnosis and/or persistent presence of serum paraprotein 1 year after treatment.

0.033), respectively. Those patients that had persistent SMP 1 year after treatment had a shorter TTM, 1.8 years versus NR compared to those who did not ( $p<0.001$; Fig. S2).

We included age, LDH, gender, $\beta 2$-microglobulin, plasmacytoma type, size, immunoparesis, SMP presence at baseline, SMP persistence at 1 year after treatment, involved/uninvolved sFLC ratio, Bence Jones proteinuria, and radiation dose in univariate analysis (Tables $\mathrm{S} 1$ and S2). SMP at baseline, its persistence after treatment, and plasmacytoma size $\geq 10 \mathrm{~cm}$. were significant in univariate analysis for TTM. Multivariate analysis backwards selection model identified both SMP persistence at 1 year and plasmacytoma $\geq 10 \mathrm{~cm}$. as independent variables for TTM rate with hazard ratios of 4.9 (95\% CI 1.9-12.5; $p=0.001)$ and $4.5(95 \% \mathrm{CI}=1.4-14.5 ; p<0.012)$, respectively (Table S3 and Fig. S3). We used these two variables to create a model predicting the rate of progression to MM. Sixty-six patients with available data were included in this model (Table S4 and Fig. 1).

The median PFS for the entire cohort was 9.4 years (0.3-19.5 years). Baseline immunoparesis and presence of paraprotein at diagnosis and at 1 year after treatment were associated with unfavorable PFS. For these factors, the median PFS was 10 versus 6 years $(p=0.043)$, NR versus 4.5 years $(p<0.001)$, and NR versus 1.8 years $(p<0.001)$, respectively (Table S5/S6 and Fig. S3).

At the median follow-up time, 23 out of 71 patients (32\%) had died (14/50 (28\%) patients in SBP and 9/21
(42\%) patients in SEP). In the SBP and SEP group, six ( $n$ $=6 / 14 ; 43 \%)$ vs three $(n=3 / 9 ; 33 \%)$ patients had a plasma cell disorder related death, respectively $(p=0.904)$. SBP patients were more likely to have a plasma cell disorder related death when compared to SEP patients. Because the cause of death was unknown in half of the patients: $35 \%(n=5 / 14)$ in SBP and 55\% $(n=5 / 9)$ in SEP, it is difficult to draw conclusions regarding this.

The median OS for the entire cohort was NR with 10year OS of $76 \%$. No OS difference was observed between SBP and SEP with a 10-year OS of 77 and $74 \%(p=0.437)$, respectively. Patients with plasmacytoma size $\geq 10 \mathrm{~cm}$ had poorer OS (Table S7/S8 and Fig. S3).

Our study demonstrated comparable 3- and 5-year SP progression rates to MM with previous studies (14-38 and $45 \%$, respectively) and confirmed that SBP patients have a shorter TTM than SEP patients. SBP tended to have worse PFS than SEP in our cohort, however it was not statistically significant $(p=0.263)^{7-9}$.

Several studies identified the presence of paraprotein at diagnosis, abnormal involved sFLC ratio, OMD, and residual paraprotein after treatment as poor prognosis factors for progression to $\mathrm{MM}^{7,10,11}$. Surprisingly, OMD did not predict progression in our cohort. This could be explained by flow analysis sensitivity in comparison to other published studies. For example, Paiva et al. used additional markers including CD20, CD27, CD28, CD81, and CD117 to determine clonality, which were not used in 
our analysis ${ }^{7}$. The impact of plasmacytoma size remains controversial. Our study found that patients with plasmacytomas $\geq 10 \mathrm{~cm}$ had unfavorable TTM, PFS, and OS. These patients may need treatment with higher RT doses for bulkier tumors and/or the addition of systemic therapy to local RT control.

This model (plasmacytoma $>10 \mathrm{~cm}$. and persistence of paraprotein 1 year after diagnosis) predicted, in our cohort, the progression risk to MM in SP patients (19\% vs $65 \%, 30 \%$ vs $70 \%$, and $39 \%$ vs $82 \%$ in patients with 0 and 1 or 2 factors, respectively). These rates are very similar (and even higher) than published rates of progression from studies for high-risk smoldering MM (SMM). Two randomized studies have shown improved PFS in SMM patients treated with lenalidomide \pm dexamethasone ${ }^{2,3}$. One of these studies has also shown better OS for patients treated with lenalidomide/dexamethasone versus observation $^{3}$. Adjuvant systemic therapy after radiation for SP patients to decrease the rate of progression to MM has been studied in the past. In 2019, a cooperative group study of 110 patients with SBP randomized to either ixazomib, lenalidomide, dexamethasone with zoledronic acid vs zoledronic acid (NCT02516423) after radiation therapy in the USA, was stopped due to lack of accrual. Thus, most studies investigating adjuvant therapy in SBP are either retrospective and/or in a small number of patients and the results remain controversial ${ }^{12-14}$. A recently published study of 61 SBP patients following a modern definition of plasmacytoma in France compared 37 patients treated with RT alone to 24 patients treated with the combination of RT and various adjuvant agents $^{15}$. This study demonstrated a PFS benefit of the combination treatment, particularly in patients younger than 60 years of age.

Our study has several limitations including the retrospective nature of our data, no known cause of death for about half of the patients, inability to analyze SBP and EMP separately due to small EMP cohort size and absence of molecular/genetic analysis of plasmacytomas. Despite this, all patients underwent advanced imaging, BM MFC testing, and met IMWG 2014 criteria. We describe an easy to use clinical model including two variables: plasmacytoma $>10 \mathrm{~cm}$. at baseline and persistence of paraprotein after one year after treatment to predict progression to $\mathrm{MM}$ and may provide insights into the progression of patients in the clinic. These data need to be validated in other cohorts. International efforts are needed to lead adjuvant treatment studies in solitary plasmacytoma.

\section{Acknowledgements}

This work was also supported in part by The MD Anderson Cancer Center Support Grant (P30 CA016672), the Leukemia and Lymphoma Society Specialized Center of Research (LLS SCOR), the Dr. Miriam and Sheldon G. Adelson Medical Research Foundation, the Multiple Myeloma Research Foundation, The Chapman Perelman Foundation, and the University of Texas
MD Anderson Moon Shot Program. RZO, the Florence Maude Thomas Cancer Research Professor, would like to acknowledge support from the National Cancer Institute (R01s CA184464 and 194264, and U10 CA032102), the Leukemia \& Lymphoma Society (SCOR-12206-17), the Brock Family Myeloma Research Fund, and the Jean Clarke High-Risk Myeloma Research Fund. We would like to thank participating patients and their families.

\section{Author details}

'Department of Lymphoma/Myeloma, The University of Texas MD Anderson Cancer Center, Houston, TX, USA. ${ }^{2}$ Faculty of Medicine Siriraj Hospital, Division of Hematology, Mahidol University, Salaya, Thailand. ${ }^{3}$ Department of Radiation Oncology, The University of Texas MD Anderson Cancer Center, Houston, TX, USA. ${ }^{4}$ Department of Radiodiagnostic Imaging, The University of Texas MD Anderson Cancer Center, Houston, TX, USA. ${ }^{5}$ Department of Biostatistics, The University of Texas MD Anderson Cancer Center, Houston, TX, USA

\section{Author contributions}

E.E.M. designed the research, analyzed data, and wrote the manuscript. C.K. analyzed data and wrote the manuscript. C.M.C. analyzed data. H.L. contributed patients and gave manuscript comments. S.T. contributed patients and gave manuscript comments. J.G. contributed patients and gave manuscript comments. C.C.P. contributed patients and gave manuscript comments. B.S.D. contributed patients and gave manuscript comments. B.A. contributed patients and gave manuscript comments. R.A. contributed patients and gave manuscript comments. R.Z.O. contributed patients and gave manuscript comments. W.D. analyzed the data. L.F. analyzed the data. D.M.W. designed the research and provided manuscript comments.

\section{Conflict of interest}

E.M. has received research support from Sanofi, Quest Diagnostics, Novartis, JW Pharma, Merck; consultant fees from Takeda, Celgene, Sanofi, Janssen and Adaptive Biotechnologies. C.K. reports no conflicts of interest. C.M.C. reports no conflicts of interest. H.L. has received consulting fees from Adaptive Biotechnologies, Celgene, Pimera, and Takeda, and research support from Amgen, Daiichi Sankyo, Janssen, and Takeda. S.T. reports no conflicts of interest. J.G. reports no conflicts of interest. C.C.P. reports no conflicts of interest. B.S.D. reports no conflicts of interest. B.A. reports no conflicts of interest. R.A. reports no conflicts of interest. R.O. has received consulting fees from Amgen, Bristol-Myers-Squibb, Celgene, GSK Biologicals, lonis

Pharmaceuticals, Janssen, Juno Therapeutics, Kite Pharma, Legend Biotech, Molecular Partners, Sanofi, Servier, and Takeda and research support from BioTheryX. W.D. reports no conflicts of interest. L.F. reports no conflicts of interest. D.W. reports no conflicts of interest.

\section{Publisher's note}

Springer Nature remains neutral with regard to jurisdictional claims in published maps and institutional affiliations.

Supplementary information The online version contains supplementary material available at https://doi.org/10.1038/s41408-021-00419-1.

Received: 30 June 2020 Revised: 17 August 2020 Accepted: 18 January 2021

Published online: 08 February 2021

\section{References}

1. Knobel, D. et al. Prognostic factors in solitary plasmacytoma of the bone: a multicenter Rare Cancer Network study. BMC Cancer 6, 118 (2006).

2. Lonial, S. et al. Randomized trial of lenalidomide versus observation in smoldering multiple myeloma. J. Clin. Oncol. 38, JCO1901740 (2019).

3. Mateos, M. V. et al. Lenalidomide plus dexamethasone for high-risk smoldering multiple myeloma. N. Engl. J. Med. 369, 438-447 (2013).

4. Manasanch E. et al. A multicenter phase II single arm trial of isatuximab in patients with high risk smoldering multiple myeloma (HRSMM). Blood abs 3116 Presented at ASH 2019 Annual Meeting (American Society Of Hematology, Orlando, FL. 2019).

5. Manasanch, E. E. et al. A pilot study of pembrolizumab in smoldering myeloma: report of the clinical, immune, and genomic analysis. Blood Adv. 3 2400-2408 (2019). 
6. Rajkumar, S. V. et al. International Myeloma Working Group updated criteria for the diagnosis of multiple myeloma. Lancet Oncol. 15, e538-e548 (2014).

7. Paiva, B. et al. Multiparameter flow cytometry for staging of solitary bone plasmacytoma: new criteria for risk of progression to myeloma. Blood 124 1300-1303 (2014).

8. Nahi, H. et al. Incidence, characteristics, and outcome of solitary plasmacytoma and plasma cell leukemia. Population-based data from the Swedish Myeloma Register. Eur. J. Haematol. 99, 216-222 (2017).

9. Ozsahin, M. et al. Outcomes and patterns of failure in solitary plasmacytoma: a multicenter Rare Cancer Network study of 258 patients. Int. J. Radiat. Oncol. Biol. Phys. 64, 210-217 (2006).

10. Dingli, D. et al. Immunoglobulin free light chains and solitary plasmacytoma of bone. Blood. 108, 1979-1983 (2006).
11. Dimopoulos, M. A., Goldstein, J., Fuller, L., Delasalle, K. \& Alexanian, R. Curability of solitary bone plasmacytoma. J. Clin. Oncol. 10, 587-590 (1992).

12. Holland, J., Trenkner, D. A., Wasserman, T. H. \& Fineberg, B. Plasmacytoma Treatment results and conversion to myeloma. Cancer. 69, 1513-1517 (1992).

13. Shih, L. Y., Dunn, P., Leung, W. M., Chen, W. J. \& Wang, P. N. Localised plasmacytomas in Taiwan: comparison between extramedullary plasmacytoma and solitary plasmacytoma of bone. Br. J. Cancer 71, 128-133 (1995).

14. Aviles, A., Huerta-Guzman, J., Delgado, S., Fernandez, A. \& Diaz-Maqueo, J. C. Improved outcome in solitary bone plasmacytomata with combined therapy. Hematol. Oncol. 14, 111-117 (1996).

15. Mheidly, K. et al. New insights in the treatment of patients with solitary bone plasmacytoma. Leuk. Lymphoma 60, 2810-2813, https://doi.org/10.1080/ 10428194.2019.1605067 (2019). 